\title{
Under-Graduate Oncology Education in Iraq: Roadmap for Improvement
}

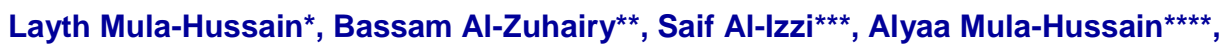 \\ Muzahm Al-Khyatt***** \\ *The Ottawa Hospital Cancer Centre - Faculty of Medicine, University of Ottawa, Ottawa -

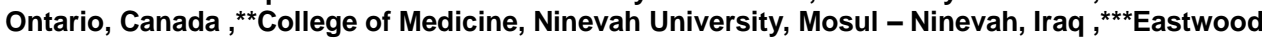

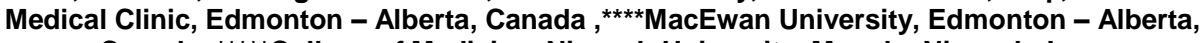 \\ Canada,${ }^{* \star \star \star \star}$ College of Medicine, Ninevah University, Mosul - Ninevah, Iraq. \\ Correspondence: LMulaHussain@AOL.com
}

(Ann Coll Med Mosul 2020; 42 (1):90-98).

Received: $19^{\text {th }}$ June 2020; Accepted: $13^{\text {th }}$ July 2020.

\section{ABSTRACT}

Oncology is a branch of medicine that specializes in the diagnosis and treatment of cancer, and is divided into surgical oncology, radiation oncology and medical oncology. Cancer is one of the leading causes of morbidity and mortality worldwide and there is a distinct shortage of adequately qualified oncologists in Iraq. Oncology education should be introduced at the beginning of medical school (college) as every doctor may face cancer patients in their training and practice after graduation. However, there is a gap in this area, as this branch is relatively new compared to other clinical branches. Holistic cancer care and a patient-centered approach should be the goal of modern oncology. Comprehensive under-graduate oncology education should be a critical component in medical education. This work is aiming to present a roadmap for an ideal oncology curriculum, which can be integrated and implemented into the Iraqi medical schools' curricula.

KEYWORDS: Cancer, Curricula, Iraq, Oncology, Undergraduate Medical Education.

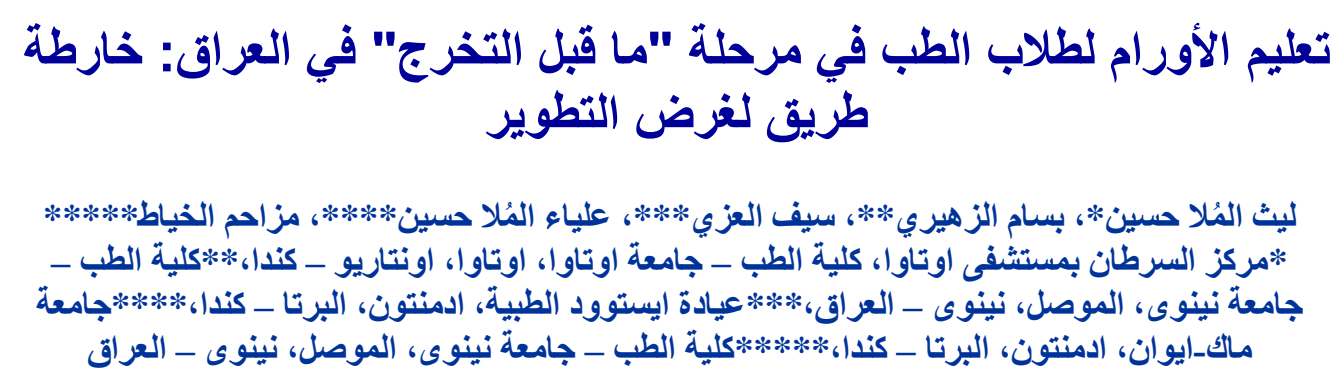

الخلاصة

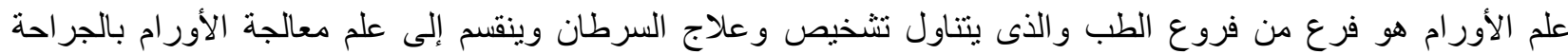

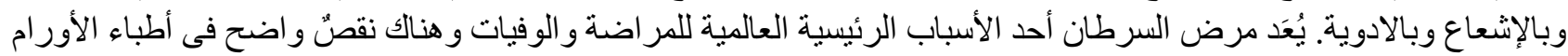

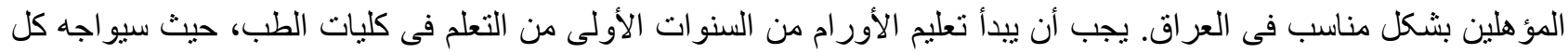

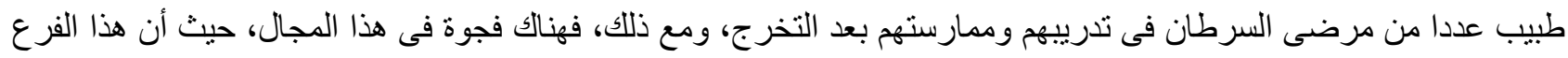

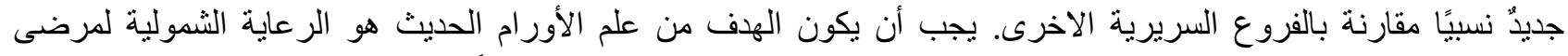

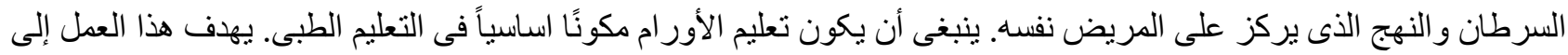

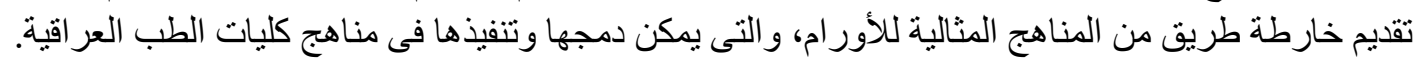

الكلمات المفتاحية: سرطان، مناهج، العر اق، علم الأورام، التعليم الطبى فى المرحلة الجامعية. 


\section{BACKGROUND}

ncology is a branch of medicine that specializes in the diagnosis and treatment of cancer. Historically, it started with surgical oncology, but evolved tremendously after the mid $19^{\text {th }}$ century with the start of anesthesia in 1846 . This was followed by radiation oncology in the early $20^{\text {th }}$ century, in particular, after the birth of $X$ ray and radioisotopes in 1895/1896, and then medical oncology in the mid $20^{\text {th }}$ century. Today, cancer treatment usually necessitates multidisciplinary inputs from the three specialities. Of those cancer patients who are cured, it is estimated that approximately $49 \%$ are cured by surgery, $40 \%$ by radiotherapy alone or combined with other modalities, and $11 \%$ by chemotherapy alone or combined ${ }^{1}$.

Cancer is increasingly becoming one of the leading causes of mortality worldwide as the population ages and many educators have drawn attention to the need for oncology education at the under- and post-graduate levels to cover the increasing need of this disease ${ }^{2,3}$. Properly educated medical students will be in a better position after graduation to understand and subsequently manage the cancer patients as undergraduate education is the most important step to create good physicians. It is important that all medical students learn about cancer as all doctors encounter such patients every now and then ${ }^{4-7}$. However, there is no universal consensus on what should be learned at the under-graduate oncology education (UGOE) level, or what the best and most appropriate teaching methods are $^{8}$. In 1988, the European Organization for Research and Treatment of Cancer (EORTC) proposed a curriculum in oncology for medical students in Europe. The main reasons for this were: (i) the recognized deficiency of undergraduate cancer education in many European medical schools; and (ii) the need to ensure that newly qualified doctors possess adequate skills to deal with prevention, early diagnosis, curative management and palliative care $^{9}$. Also, there is an increasing emphasis on teaching and assessing values, attitudes, and beliefs in clinical care during the undergraduate medical education ${ }^{8,10}$.

In fact, oncologists may struggle to serve the needs of the growing number of cancer patients unless more medical students can be engaged into these cancer specialties. The interest of medical students in this field is not optimal in many countries, including Iraq. The latest published Iraqi Health Report in 2017, revealed that there is a total of 128 medical and radiation oncologists ${ }^{11}$. This amounts to less than 4 cancer specialists per million population (vs. average of 10 per million population internationally). An additional 320 cancer specialists are needed in the short term (as Iraqi population is estimated to be around 40 million in 2020), a need that will grow due to the increasing population and increased cancer detection. Similarly, there is a shortage in surgical oncologists, onco-nurses, nutritionists, psychotherapists, etc ${ }^{12}$. Cancer is the third leading cause of death in Iraq (after stroke and heart diseases). The crude incidence rate has doubled over four decades (from 40.19/100,000 in 1979 to $82.62 / 100,000$ in 2018). There were 31,502 registered cases in 2018 (57\% females), while deaths resulting from cancer in that year were 10,293 ( $51 \%$ males). The top five cancers were of: breast, lung, colorectum, blood, and urinary bladder. The top five fatal cancers were of: lung, breast, blood, central nervous system, and colorectum $^{13}$. Mortality to Incidence Ratio (MIR) from the above data is 0.33 .

This work is backed by another study by the first author, titled (Undergraduate Oncology Education: mini-literature review with single institution experience from Iraq), which was released in $2015^{14}$. One can notice that UGOE in Iraq needs an improvement at different aspects (like amount of knowledge and its extent, content and its depth, teaching methods and holistic approaches, etc.) and that work came to the conclusion that a proposal for comprehensive improvement might be a good step in this direction. The aim of this work is to present a suggested curriculum of UGOE that may be used as a model to be implemented in medical schools (or colleges as usually named in Iraq). The core of this work is basically extracted from an Australian experience, besides the first experience at the Tikrit Medical College in 2013 $2014^{14}$, which was followed by the second experience at the Ninevah Medical College in 2018 $-2019$. 


\section{MATERIALS AND METHODS}

A literature search was performed on June 13, 2020, about the indexed papers at www.PubMed.gov using the search the terms (Undergraduate Oncology Education) filtered by (Review). Forty-three (43) results appeared during the period $1993-2020$. Ten papers were reviewed due to their immediate relevance of this search, in addition to a core reference of this work, Ideal Oncology Curriculum for medical schools ${ }^{15}$, and other related references. The work is a descriptive mini-review of the subject.

\section{RESULTS}

The authors suggest arranging the roadmap improvement's steps in two phases; the $1^{\text {st }}$ phase for the first year as a pilot, in about $10-14$ theoretical hours, and to be followed by the $2^{\text {nd }}$ phase for the following years that will be expanded to 21 - 30 theoretical hours. Table 1 shows a summary of the objectives for the latter phase. From the formerly mentioned study in 2015, two surveys were arranged (pre-course and postcourse) in order to explore the benefit of the pilot education course that was launched in Tikrit Medical College. Participants were 40 in total. Male:Female ratio was 1.4:1. Comparison of the two surveys (Table 2), $17 \%$ of the students plan to choose oncology as a future career and 54\% indicated that the current oncology hours are not sufficient (that is ranged $6-9$ hours/annum). After the course, $51 \%$ mentioned that oncology hours should be ranged ( $8-25$ hours/annum) and $84 \%$ of them stated that setting oncology standards is useful. Topics that should be included as core competencies in the UGOE syllabus are in sequence: diagnosis and treatment of cancer, basics of oncology and public health, general knowledge of common malignancies and finally the complications, prognosis, and communication in oncology (Figure 1).
Table 1: Areas, objectives, and topics that need to be covered in the suggested oncology curriculum ${ }^{15}$

\begin{tabular}{|c|c|c|}
\hline Area & Objective & Topic \\
\hline \multirow[t]{2}{*}{ Public Health } & 1.1 & $\begin{array}{c}\text { Population, } \\
\text { epidemiology and } \\
\text { risk factors }\end{array}$ \\
\hline & 1.2 & $\begin{array}{l}\text { Prevention, } \\
\text { screening, and } \\
\text { family risk }\end{array}$ \\
\hline \multirow[t]{4}{*}{ Cancer biology } & 2.1 & Anatomy \\
\hline & 2.2 & Physiology \\
\hline & 2.3 & Pathology \\
\hline & 2.4 & Biology \\
\hline \multirow[t]{3}{*}{$\begin{array}{c}\text { Patient } \\
\text { management }\end{array}$} & 3.1 & $\begin{array}{c}\text { Patient } \\
\text { management }\end{array}$ \\
\hline & 3.2 & $\begin{array}{l}\text { Quality of life and } \\
\text { therapeutic ratio }\end{array}$ \\
\hline & 3.3 & $\begin{array}{l}\text { Information } \\
\text { management }\end{array}$ \\
\hline \multirow[t]{2}{*}{ Diagnosis } & 4.1 & $\begin{array}{c}\text { Clinical } \\
\text { examination }\end{array}$ \\
\hline & 4.2 & $\begin{array}{c}\text { The diagnostic } \\
\text { process }\end{array}$ \\
\hline \multirow[t]{6}{*}{ Treatment } & 5.1 & $\begin{array}{c}\text { General principles } \\
\text { of treatment }\end{array}$ \\
\hline & 5.2 & $\begin{array}{c}\text { Principles of } \\
\text { surgery }\end{array}$ \\
\hline & 5.3 & $\begin{array}{l}\text { Principles of } \\
\text { radiotherapy }\end{array}$ \\
\hline & 5.4 & $\begin{array}{c}\text { Principles of } \\
\text { systemic therapy }\end{array}$ \\
\hline & 5.5 & $\begin{array}{c}\text { Principles of } \\
\text { palliative care }\end{array}$ \\
\hline & 5.6 & $\begin{array}{l}\text { Follow-up and } \\
\text { relapse }\end{array}$ \\
\hline \multirow[t]{4}{*}{$\begin{array}{c}\text { Communication } \\
\text { skills } \\
\end{array}$} & 6.1 & $\begin{array}{l}\text { Psychosocial and } \\
\text { cultural aspects }\end{array}$ \\
\hline & 6.2 & $\begin{array}{l}\text { Communication } \\
\text { and counselling }\end{array}$ \\
\hline & 6.3 & $\begin{array}{l}\text { Education of } \\
\text { patients }\end{array}$ \\
\hline & 6.4 & $\begin{array}{c}\text { Family and } \\
\text { community } \\
\text { support }\end{array}$ \\
\hline Ethics & 7 & $\begin{array}{c}\text { Ethics and } \\
\text { professionalism }\end{array}$ \\
\hline $\begin{array}{c}\text { Clinical } \\
\text { experience }\end{array}$ & 8 & $\begin{array}{c}\text { Five essential } \\
\text { cancer's clinical } \\
\text { experiences }\end{array}$ \\
\hline
\end{tabular}


Table 2: Results of pre-course and post-course surveys ${ }^{14}$.

\begin{tabular}{|c|c|c|c|}
\hline Survey items & Pre-Course responses & $\begin{array}{l}\text { Post-Course } \\
\text { responses }\end{array}$ & Comparison \\
\hline Number of Students & 41 & 37 & Average: 39 \\
\hline Sex (Male/Female) & $26 / 15(1.7 / 1)$ & $20 / 17(1.2 / 1)$ & $\mathrm{M} / \mathrm{F}: 1.4 / 1$ \\
\hline Oncology as a career? (Yes/No) & $7 / 34(17 \% / 83 \%)$ & $5 / 32(14 \% / 86 \%)$ & --- \\
\hline $\begin{array}{l}\text { Current hours of oncology } \\
\text { education }\end{array}$ & Range 6-9 hours & --- & --- \\
\hline $\begin{array}{l}\text { Ideality of current hours of oncology } \\
\text { education? (Yes/No) }\end{array}$ & $\begin{array}{l}\text { Yes }=19(46 \%) \\
\mathrm{No}=22(54 \%)\end{array}$ & $\begin{array}{l}\text { Yes }=18(49 \%) \\
\mathrm{No}=19(51 \%)\end{array}$ & $\begin{array}{l}P \text { value }=0.791^{\star} \\
P \text { value }=0.785^{\star}\end{array}$ \\
\hline $\begin{array}{l}\text { Expected ideal hours of oncology } \\
\text { education per annum? }\end{array}$ & $\begin{array}{l}\text { Range } 12-70 \text { hours } \\
\text { Mean } \pm \text { SD }(32.5 \pm \\
12.9)\end{array}$ & $\begin{array}{l}\text { Range 8-25 hours } \\
\text { Mean } \pm \text { SD }(17.9 \pm 9.3)\end{array}$ & $\begin{array}{l}P \text { value }= \\
0.001^{* *}\end{array}$ \\
\hline $\begin{array}{l}\text { Is there is a set of oncology } \\
\text { objectives? (Yes/No) }\end{array}$ & 28/12 [1 empty] & --- & --- \\
\hline $\begin{array}{l}\text { Is there is an oncology curriculum } \\
\text { at your medical school? (Yes/No) }\end{array}$ & 22/18 [1 empty] & --- & --- \\
\hline $\begin{array}{l}\text { Is there is a recommended } \\
\text { oncology textbook or reference? } \\
\text { (Yes/No) }\end{array}$ & $18 / 23$ & --- & --- \\
\hline $\begin{array}{l}\text { Would a standard set of oncology } \\
\text { objectives, curriculum, and } \\
\text { reference resource be useful? } \\
\text { (Yes/No) }\end{array}$ & $\begin{array}{l}\mathrm{Yes}=29(72.5 \%) \\
\mathrm{No}=11(27.5 \%)\end{array}$ & $\begin{array}{l}\mathrm{Yes}=31(88.6 \%) \\
\mathrm{No}=4(11.4 \%)\end{array}$ & $\begin{array}{l}P \text { value }=0.087^{\star} \\
P \text { value }=0.079^{\star}\end{array}$ \\
\hline $\begin{array}{l}\text { Would you attend a voluntary } \\
\text { summer oncology course? } \\
\text { (Yes/No) }\end{array}$ & $14 / 27$ & $18 / 19$ & --- \\
\hline
\end{tabular}

* Independent two samples t-test (for the difference between two means)

** Independent two samples z-test (for the difference between two proportions)

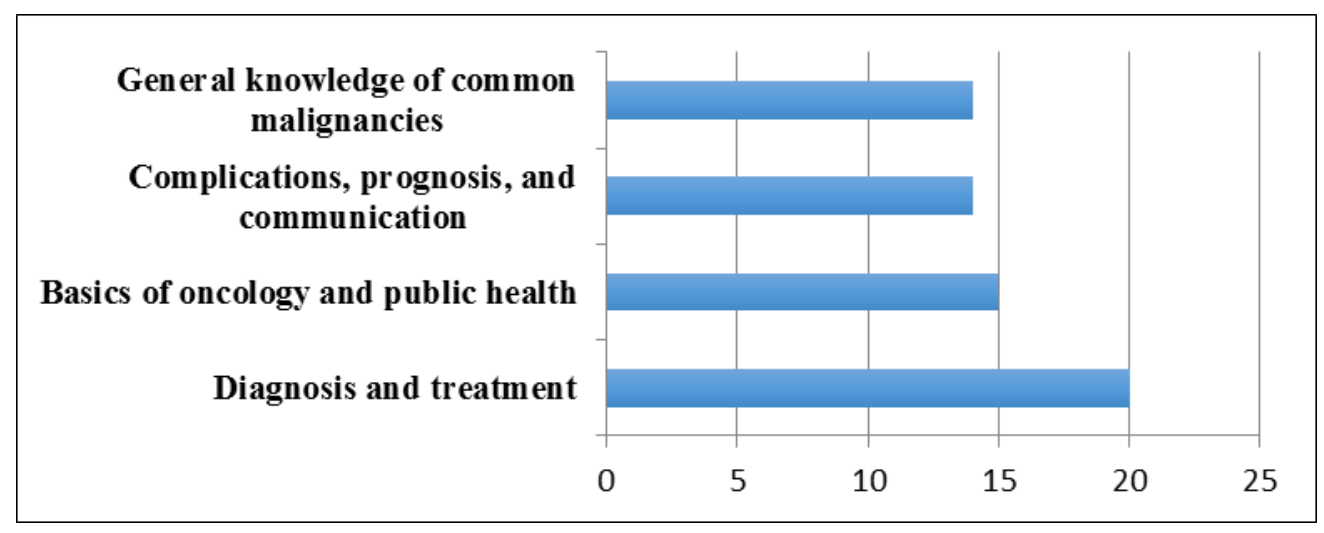

Figure 1: Topics that should be included as core competencies in oncology to medical students ${ }^{14}$ 
$1^{\text {st }}$ Phase: This phase will include the following topics: Cancer and oncology: Introductions; Cancer awareness, prevention and early detection; Patients' rights, ethics and communication skills in oncology; Cancer patients' care: global and local perspectives; Surgical oncology; Radiation oncology; Adult medical oncology; Pediatric medical oncology; Palliative and supportive oncology; Integrated oncology and the comprehensive holistic cancer care concepts.

2nd Phase: This phase will be a comprehensive curriculum that aims to identify core skills and competencies in oncology that graduating medical students should possess. In whatever way it may be integrated, the material will assist in providing for the introduction of patient-centered skills simultaneously with a range of technical skills in an iterative process, rather than the more traditional educational model. At graduation, the student will be competent in the following areas ${ }^{10,15}$ :

\section{PUBLIC HEALTH}

Population, epidemiology and risk factors: a) Appreciate the significance of cancer as a health problem; b) Describe the epidemiological concepts of morbidity, mortality, relative risk and survival in relation to common cancers; c) Discuss the role of statistical information, including surveillance; d) Discuss the purpose of cancer registries; e) Describe risk factors; f) List the most frequently diagnosed malignancies nationally and globally; g) Describe the differential rates of cancers and their outcomes.

Prevention, screening and family risk: a) Describe methods for primary and secondary prevention; b) Demonstrate an understanding of the scientific evidence for the utility of screening; c) Discuss environmental control, behavioural and chemical approaches to the prevention of cancer; d) Demonstrate an understanding of the psychosocial impact of screening and staging investigations on the patient; e) Demonstrate ability to take family history.

\section{CANCER BIOLOGY}

Anatomy: Demonstrate an understanding of the anatomical basis of cancer assessment such as: vascular supply, lymphatic drainage, and anatomical relationships of relevance.
Physiology: Describe the principles of drug metabolism and handling of carcinogens.

Pathology: a) Describe the concept of carcinogenesis; b) For the common cancers, demonstrate an understanding of microscopic and macroscopic findings; c) Describe patterns of spread of common cancers; d) Demonstrate an understanding of the role and purpose of molecular pathology.

Biology: a) Demonstrate an understanding of the molecular genetics of cancer; b) Demonstrate an understanding of the molecular correlates of the pathological progression of cancer; c) Describe hormonal influences and tumour markers; d) Identify important familial cancer syndromes.

\section{PATIENT MANAGEMENT}

Patient management: a) Demonstrate awareness of clinical practice guidelines, evidence-based medicine and multidisciplinary management team; b) Identify effective means of communication; c) Demonstrate an understanding of managing psychological distress in the patient and the relatives; d) Recognise the importance of coordinated care; e) Demonstrate an ability to seek help at an appropriate level of urgency; f) Demonstrate an attitude of accepting responsibility for ensuring continuity of care; g) Describe the integration of treatment modalities; h) Survey treatment options available to the patient; j) Demonstrate an understanding of the range of medical and non-medical health professionals involved in cancer care.

Quality of life and therapeutic ratio: a) Understand how quality of life is assessed; b) Appreciate the balance of risks and benefits of treatment versus observing the cancer; c) Demonstrate an understanding of the concepts of cost effectiveness; d) Demonstrate an understanding of the concept of therapeutic ratio; e) Assess the effects of clinical decisions about treatment on patients, their families, and the health care system; f) Demonstrate an awareness of supportive care networks.

Information management: a) Demonstrate an understanding to critically appraise evidences; $b$ ) Appraise information from patients and other subjective sources critically; c) Adapt and apply information to the management of individual cases; d) Demonstrate an understanding of clinical trials 
and their importance; e) Appraise studies of treatment, prevention, diagnosis, prognosis, causation and harm, systematic reviews, clinical practice guidelines and cost-effectiveness studies; f) Demonstrate an understanding of the limits of evidences; g) Discuss unproven or alternative/complementary therapies in a way that encourages patients to appraise their claimed benefits and their costs in a critical manner.

\section{DIAGNOSIS}

Clinical examination: a) Discuss clinical manifestations of cancer; b) Demonstrate effective clinical examination relevant to common cancers; c) Describe the results of clinical examination.

The diagnostic process: a) Demonstrate an understanding of the wide range of potential presentations of cancer, and be open to unusual presentations; b) Take history and conduct a physical examination, tailoring the latter to natural history and patterns of spread; c) Assess performance status; d) Discuss the differential diagnosis; e) Describe how to establish a diagnosis of cancer and outcome overview; f) Demonstrate an understanding of the histopathological classification and staging of cancers and the implications of staging for prognosis and treatment; g) Recognise common complications of malignant disease; h) Critically evaluate cost effectiveness of investigations.

\section{TREATMENT}

General principles of treatment: a) Demonstrate recognition of the importance of the patient in the decision-making process; b) Describe the principles of treatment with intent to cure and palliate; c) Demonstrate the principles of patientfocused care; d) Demonstrate awareness of outcome measures; e) Demonstrate an understanding of the management of potential complications of cancer treatments and common oncological emergencies.

Principles of surgery: a) Describe the aims of surgical treatment of cancers and its general principles and indications; b) Demonstrate an understanding of the range of surgical options and the ways these are affected by the integration into multi-modality care; c) Evaluate the outcomes of surgery; d) Discuss interactions with other modalities of therapy, both pre- and postoperatively.

Principles of radiotherapy: a) Describe the principles of radiobiology and radiotherapy; b) Describe radiation treatment equipment and approaches; c) Recognise the clinical indications for radiotherapy; d) Evaluate the outcomes of radiotherapy; e) Recognise the common complications of radiotherapy and understand their management; f) Discuss the integration of radiotherapy with other modalities; g) Demonstrate an understanding of the access problems associated with radiotherapy and how this may affect patient choice.

Principles of systemic therapy: a) Outline the principles of systemic therapy; b) Recognise clinical indications for use of systemic therapy; c) Evaluate the outcomes of systemic therapy; d) Demonstrate ability to assess response to systemic therapy; e) Recognise the common toxicities and complications of systemic therapy and understand their management; f) Discuss the integration of systemic therapy with other modalities.

Principles of palliative care: a) Demonstrate an understanding of the importance of the patient in decision making processes; b) Explain the role and structure of palliative and supportive care in the multidisciplinary management of advanced cancer; c) Demonstrate the assessment of pain and other symptoms; d) Discuss principles of both pharmacological and non-pharmacological relief measures; e) Demonstrate an understanding of "end of life" issues; f) Demonstrate adequate communication skills.

Follow-up and relapse: a) Demonstrate an understanding of the aims and limitations of followup; b) Describe patterns and manifestations of recurrences and their management; c) Demonstrate an understanding of the psychosocial impact of expected and unexpected recurrences.

\section{COMMUNICATION SKILLS}

Psychosocial and cultural aspects: a) Discuss cultural and psychosocial factors influencing presentation for screening, diagnosis, and treatment on the patient and family; b) Discuss the economic impact of cancer on the patient and family; c) Demonstrate an understanding of the impact of cancer on sexuality and fertility; d) Be 
aware of significant cultural, spiritual and religious differences that frame the challenge of breaking bad news; e) Demonstrate understanding of resources offering appropriate patient support information.

Communication and counselling: a) Illustrate an ability to communicate the bad news; b) Be aware that the impact of receiving bad news interferes with patients' ability to comprehend fully the important information; c) Provide supportive counselling for the patient and care givers; d) Facilitate informed consent.

Education of patients: a) Demonstrate an understanding of the principles and benefits of educating patients to be actively involved in their care; b) Demonstrate an understanding of resources available to patients and the public and its limitations; c) Discuss the doctor's role in patient education about self-examination and worrying signs; d) Promote preventive medicine; e) Develop a partnership approach.

Family and community support: a) Discuss the role of psychosocial, physical, financial and information supports for patients and their families; b) Demonstrate an understanding of the means by which doctors can facilitate the provision of these services; d) Identify the impact on the family of a shift to home care.

\section{ETHICS}

Ethics and professionalism: a) Demonstrate an understanding of the effects on health professionals of caring for patients with cancer and of the ways in which the stresses of this work can be managed appropriately; b) Discuss the bioethics of issues such as access, equity and resource allocation, as well as medical care at the end of life; c) Discuss principles, elements and role of informed consent in patient decision making.

\section{CLINICAL EXPERIENCE}

Five cancers: a) Talking with and examining people affected by all stages of cancer; b) Talking with and examining people affected by common cancers in Iraq "breast, lung, colorectum, leukemia and urinary bladder"; c) Observing all components of multidisciplinary care; d) Seeing shared decision-making between people with cancer and their doctors; e) Talking with and examining dying people.

\section{DISCUSSION}

This work is aiming to present a suitable plan to integrate a holistic oncology curriculum to the undergraduate medical education in Iraq. The core of this report is mostly based on the Australian "Ideal Oncology Curriculum" in 2007, the experience at Tikrit Medical College in 2013 $2014^{14,15}$, and the Ninevah Medical College in 2018 - 2019 in Iraq, with some modifications that can make the UGOE curricula as practical as possible in a two phased implementation process. The goal is that adequate oncology education must be an integral component of medical school curricula if students are to achieve learning outcomes that meet the needs of the future population ${ }^{16}$. We think that this report is the first one of its kind in the Iraqi medical literature.

During the last decades, academic bodies in many countries questioned medical students to assess teaching about cancer in their own medical schools. Most results demonstrated that appropriate integration of oncology is limited in many medical schools ${ }^{17}$. The target of UGOE should not only be the provision of updated medical knowledge, but also the development of a proper attitude towards all cancer-related issues ${ }^{18}$. There is a pressing need to intervene, in multiple ways, to improve oncology teaching in the various medical schools worldwide. This is especially important for developing countries, where the burden of cancer is increasing ${ }^{19}$. Our preliminary local findings point to a trend that the current UGOE in Iraq warrants further development ${ }^{14}$. This report is aiming to help Iraqi universities to establish their own UGOE curricula and highlights a roadmap for improvement in this field.

The Australian "Ideal Oncology Curriculum"15 was published in 2007 by a multidisciplinary group of cancer clinicians and educators. It provided a comprehensive checklist for course design that allows adaptation to local conditions, as well as a checklist against which outcomes can be monitored $^{20}$. This was followed by the development of the web book "Clinical Oncology for Medical Students", which aimed to provide oncology overview to medical students at their level rather than at a trainee level ${ }^{21}$.

As a critical component of cancer treatment triangle, Dennis and Duncan emphasized that teaching radiation oncology should begin early in 
the undergraduate process, be mandatory for all students, and should impart knowledge relevant to future general practitioners rather than detailed information relevant only to oncologists. Educators should make use of the available model curricula and should integrate radiation oncology teaching into their existing curricula or construct stand-alone oncology rotations where the principles of radiation oncology can be conveyed. Assessments of student knowledge and curriculum effectiveness are critical ${ }^{22}$.

Despite the positive evolution in recent years, the heterogeneity in oncology contents during undergraduate education training continues to be remarkable even in some developed countries like the UK and Spain. A survey of newly graduated doctors in the UK found that only $61 \%$ of first year graduates had received oncology teaching at medical school, 31\% recalled seeing fewer than 10 patients with cancer, $15 \%$ felt they had adequate knowledge about chemotherapy and radiotherapy, and only one in ten doctors felt prepared to manage oncological emergencies ${ }^{23}$; Lara et al and Segui et al concluded in 2013 and 2019 that undergraduate medical students deserve a more coherent and modern approach to education with a strong emphasis on clinical practice and that an updated theoretical content incorporated in the clinical practice are among the recommendations for improvement in Spain ${ }^{24,25}$. Based on these two examples, we assume that improvement of UGOE is a required need across the borders and that the attention for it is not limited to the developing countries only.

Finally, novel approaches to implement oncology curricula have arisen in the literature. The application of such approaches relies upon individual medical schools and its educators to consider what is relevant to its certain circumstances. Overall, the trend of new approaches in teaching evidence-based oncology that focuses on a holistic, patient-centered approach with multidisciplinary involvement, which include clinical exposure with bedside teaching ${ }^{26}$. Obviously, integrated teamwork members of educators from the oncology side (surgical, radiation, medical, hematological, pediatric, gynecological, etc.) and the basic sciences side (in public health, imaging, pathology, etc.) is very critical for the successful implementation of the suggested curriculum of UGOE.

\section{CONCLUSIONS}

Cancer is the third cause of death in Iraq, yet probably many of the medical schools still have not yet fully modernised their approaches to curricula and rotations to better reflect the reality of the current cancer status. Comprehensive UGOE is an important component of modern medical education and filling the gap in the content and depth of the currently available approaches is not limited to one nation. This work is aiming to present a plan for optimal integration of a holistic UGOE curriculum in the Iraqi medical schools.

\section{ACKNOWLEDGEMENT}

Sincere appreciation to Mrs. Stephanie Halpenny for her English review and edits.

\section{REFERENCES}

1. International Atomic Energy Agency. Radiotherapy in Cancer Care: Facing the Global Challenge / IAEA. 1st ed. (Rosenblatt E, Zubizarreta E, eds.). Vienna: International Atomic Energy Agency; 2017. http://wwwpub.iaea.org/MTCD/Publications/PDF/P1638_we b.pdf. Accessed May 2, 2020.

2. Wild C, Weiderpass E, Stewart B, eds. World Cancer Report: Cancer Research for Cancer Prevention. Lyon, France: International Agency for Research on Cancer; 2020.

3. Tattersall $\mathbf{M H}$, Simpson JS, Langlands AO. The education of medical students about cancer-time for change. Eur J Cancer Clin Oncol. 1983;19(3):303-306.

4. Jeeva I, Jayasawal R, Kermani N, Pauri P. Oncology curriculum in developing countries and the lessons to be learned. J Clin Oncol. 2007;25(9):e12. doi:25/9/e12 [pii]

5. Gaffan J, Dacre J, Jones A. Educating undergraduate medical students about oncology: a literature review. J Clin Oncol. 2006;24(12):1932-1939. doi:10.1200/JCO.2005.02.6617

6. Robert KH, Einhorn J, Kornhuber B, Peckham $M$, Zittoun R. European undergraduate education in oncology. A report of the EORTC Education Branch. Acta Oncol. 1988;27(4):423-425.

7. Ravaud A, Hoerni B, Becouarn Y, Lagarde P, Soubeyran $P$, Bonichon F. A survey in general practice about undergraduate cancer education: results from Gironde (France). J Cancer Educ. 
$1991 ; 6(3): 153-157$ doi:10.1080/08858199109528112 [doi]

8. Tattersall $M H$, Langlands $A O$, Smith $W$, Irwig L. Undergraduate education about cancer. A survey of clinical oncologists and clinicians responsible for cancer teaching in Australian medical schools. Eur $J$ Cancer. 1993;29A(11):1639-1642.

9. Peckham M. A curriculum in oncology for medical students in Europe. Acta Oncol. 1989;28(1):141-147.

10. Tattersall $\mathrm{MH}$, Langlands $\mathrm{AO}$, Simpson JS, Forbes JF. Undergraduate education about cancer: a survey in Australian medical schools. Eur J Cancer Clin Oncol. 1988;24(3):467-471.

11. Health/Environment M of. 2017 Annual Statistical Report. Baghdad: Ministry of Health/Environment; 2018.

12. Mula-Hussain L, Alabedi $\mathrm{H}$, Al-Alloosh $\mathrm{F}$, Alharganee A. Cancer in War-Torn Countries: Iraq as an Example. In: Laher I, ed. Handbook of Healthcare in the Arab World. Cham: Springer International Publishing; 2019:1-14. doi:10.1007/978-3-319-74365-3 152-1

13. Iraqi Cancer Registry. 2018 Annual Report Iraqi Cancer Registry. Baghdad; 2018. https://moh.gov.iq/upload/upfile/ar/1090.pdf.

14. Mula-Hussain L. Undergraduate Oncology Education: mini-literature review with single institution experience from Iraq. In: Dubaybo B, ed. ACCESS Health Journal - Proceedings of the 7th International Conference on Health Issues in Arab Communities. Dearborn: The Arab Community Center for Economic and Social Services; 2015:183-194. https://www.accesscommunity.org/sites/default/fil es/documents/access-

7thhealthproceedings5b55d.pdf.

15. Oncology Education Committee. Ideal Oncology Curriculum for Medical Schools. 2nd ed. Sydney: The Cancer Council Australia; 2007. https://www.cancer.org.au/content/pdf/HealthPro fessionals/OncologyEducation/IdealOncologyCur ricDEC07-updatedcover.pdf.

16. McRae RJ. Oncology Education in Medical Schools: Towards an Approach that Reflects Australia's Health Care Needs. J cancer Educ Off J Am Assoc Cancer Educ. 2016;31(4):621625. doi:10.1007/s13187-016-1088-0

17. Pavlidis N, Vermorken JB, Costa A. Oncology for medical students: a new ESO educational avenue. Ann Oncol. 2005;16(5):840-841. doi:mdi143 [pii]

18. Karamouzis $M V$, Ifanti AA, Iconomou $G$, Vagenakis AG, Kalofonos HP. Medical students' views of undergraduate Oncology education: $A$ comparative study. Educ Health (Abingdon). 2006;19(1):61-70. doi:HT15186TK38438K2 [pii]

19. Amgad M, Shash E, Gaafar R. Cancer education for medical students in developing countries: where do we stand and how to improve? Crit Rev Oncol Hematol. 2012;84(1):122-129.

doi:10.1016/j.critrevonc.2012.01.003 [doi]

20. Koczwara B, Barton MB. The ideal oncology curriculum for medical students. J Clin Oncol. 2006;24(33):5334; author reply 5334 . doi:24/33/5334 [pii]

21. Sabesan S OI. Clinical Oncology for Medical Students. 1st ed. Sydney: Cancer Council Australia; 2014. http://wiki.cancer.org.au/oncologyformedicalstud ents.

22. Dennis KE, Duncan G. Radiation oncology in undergraduate medical education: a literature review. Int $J$ Radiat Oncol Biol Phys. 2010;76(3):649-655.

doi:10.1016/j.jrobp.2009.08.038 [doi]

23. Cave J, Woolf K, Dacre J, Potts HW, Jones A. Medical student teaching in the UK: how well are newly qualified doctors prepared for their role caring for patients with cancer in hospital? $\mathrm{Br} \mathrm{J}$ Cancer. 2007;97(4):472-478. doi:6603888 [pii]

24. Lara P, Calvo FA, Guedea F, Bilbao P, Biete A. Undergraduate cancer education in Spain: The debate, the opportunities and the initiatives of the University Forum of the Spanish Society of Radiation Oncology (SEOR). Reports Pract Oncol Radiother J Gt Cancer Cent Pozn Polish Soc Radiat Oncol. 2013;18(6):405-413. doi:10.1016/j.rpor.2013.09.003

25. Segui MA, Cruz JJ, Alba E, et al. Situation, challenges, and SEOM recommendations for the future of undergraduate education in Oncology in Spain. Clin Transl Oncol Off Publ Fed Spanish Oncol Soc Natl Cancer Inst Mex. 2020;22(7):1049-1058. doi:10.1007/s12094-01902230-8

26. Ha FJ, Parakh S. Novel Approaches To Undergraduate Oncology Education. J cancer Educ Off $J$ Am Assoc Cancer Educ. 2018;33(3):500-504. doi:10.1007/s13187-016$1109-z$ 